\title{
The effect of enteral bolus feeding on regional intestinal oxygen saturation in preterm infants is age-dependent: a longitudinal observational study
}

Sara J. Kuik ${ }^{1 *}$, Anne G. J. F. van Zoonen², Arend F. Bos ${ }^{1}$, Koenraad N. J. A. Van Braeckel', Jan B. F. Hulscher ${ }^{2}$ and Elisabeth M. W. Kooi ${ }^{1}$

\begin{abstract}
Background: The factors that determine the effect of enteral feeding on intestinal perfusion after preterm birth remain largely unknown. We aimed to determine the effect of enteral feeding on intestinal oxygen saturation $\left(\mathrm{r}_{\text {int }} \mathrm{SO}_{2}\right)$ in preterm infants and evaluated whether this effect depended on postnatal age (PNA), postmenstrual age (PMA), and/or feeding volumes. We also evaluated whether changes in postprandial $r_{\text {int }} \mathrm{SO}_{2}$ affected cerebral oxygen saturation $\left(\mathrm{r}_{\mathrm{C}} \mathrm{SO}_{2}\right)$.

Methods: In a longitudinal observational pilot study using near-infrared spectroscopy we measured $\mathrm{r}_{\text {int }} \mathrm{SO}_{2}$ and $\mathrm{r}_{\mathrm{c}} \mathrm{SO}_{2}$ continuously for two hours on postnatal Days 2 to $5,8,15,22,29$, and 36. We compared preprandial with postprandial values over time using multi-level analyses. To assess the effect of PNA, PMA, and feeding volumes, we performed Wilcoxon signed-rank tests or logistic regression analyses. To evaluate the effect on $\mathrm{r}_{\mathrm{c}} \mathrm{SO}_{2}$, we also used logistic regression analyses.

Results: We included 29 infants: median (range) gestational age 28.1 weeks (25.1-30.7) and birth weight $1025 \mathrm{~g}$ (580-1495). On Day 5, $\mathrm{r}_{\mathrm{int}} \mathrm{SO}_{2}$ values decreased postprandially: mean (SE) 44\% (10) versus 35\% (7), $P=.01$. On Day $29, \mathrm{r}_{\text {int }} \mathrm{SO}_{2}$ values increased: $44 \%$ (11) versus $54 \%(7), P=.01$. Infants with a PMA $\geq 32$ weeks showed a $\mathrm{r}_{\text {int }} \mathrm{SO}_{2}$ increase after feeding (37\% versus $51 \%, P=.04)$ whereas infants with a PMA $<32$ weeks did not. Feeding volumes were associated with an increased postprandial $r_{\text {int }} \mathrm{SO}_{2}$ (per $10 \mathrm{~mL} / \mathrm{kg}$ : $\mathrm{OR} 1.63,95 \% \mathrm{Cl}, 1.02-2.59$ ). We did not find an effect on $\mathrm{r}_{\mathrm{C}} \mathrm{SO}_{2}$ when $\mathrm{r}_{\text {int }} \mathrm{SO}_{2}$ increased postprandially.

Conclusions: Our study suggests that postprandial $r_{\text {int }} \mathrm{SO}_{2}$ increases in preterm infants only from the fifth week after birth, particularly at PMA $\geq 32$ weeks when greater volumes of enteral feeding are tolerated. We speculate that at young gestational and postmenstrual ages preterm infants are still unable to increase intestinal oxygen saturation after feeding, which might be essential to meet metabolic demands.
\end{abstract}

Trial registration: For this prospective longitudinal pilot study we derived patients from a larger observational cohort study: CALIFORNIA-Trial, Dutch Trial Registry NTR4153.

Keywords: Cerebral oxygen saturation, Enteral feeding, Feeding volumes, Fractional tissue oxygen extraction, Intestinal oxygen saturation, Postnatal age, Postmenstrual age

\footnotetext{
* Correspondence: s.j.kuik@umcg.nl

'University of Groningen, University Medical Center Groningen, Beatrix

Children's Hospital, Division of Neonatology, Groningen, the Netherlands

Full list of author information is available at the end of the article
}

(c) The Author(s). 2019 Open Access This article is distributed under the terms of the Creative Commons Attribution 4.0 International License (http://creativecommons.org/licenses/by/4.0/), which permits unrestricted use, distribution, and reproduction in any medium, provided you give appropriate credit to the original author(s) and the source, provide a link to the Creative Commons license, and indicate if changes were made. The Creative Commons Public Domain Dedication waiver (http://creativecommons.org/publicdomain/zero/1.0/) applies to the data made available in this article, unless otherwise stated. 


\section{Background}

Introducing preterm infants to enteral feeding is challenging. Gastrointestinal (GI) motility of preterm infants is limited causing delay in gastric emptying and intestinal transit. This in turn could easily result in intolerance to feeding [1]. Enteral feeding has beneficial effects on the structural and functional development of the GI tract $[1,2]$. The passage of enteral feeds leads to an increased metabolic demand on the small intestine. This results in increased intestinal perfusion from the superior mesenteric artery (SMA) known as postprandial hyperaemia [3, 4]. If this increased metabolic demand after enteral feeding cannot be met, feeding intolerance (FI) may occur, resulting in delayed full enteral feeding (FEF) and possibly even necrotizing enterocolitis (NEC) [5-8]. Furthermore, as preterm infants are at risk of impaired cerebrovascular autoregulation, postprandial redistribution of blood in favour of the intestines may result in cerebral underperfusion [9-11].

Near-infrared spectroscopy (NIRS) is a non-invasive method to assess end-organ perfusion in preterm infants $[8,12-14]$. It allows us to measure regional tissue oxygen saturation $\left(\mathrm{rSO}_{2}\right)$ continuously [12-14]. From this measure fractional tissue oxygen extraction (FTOE) can be calculated, which reflects the balance between oxygen delivery and consumption [12-14].

Recent studies on NIRS or Doppler flow measurements of the SMA reported that healthy preterm infants, who tolerate enteral feeding of at least $100 \mathrm{~mL} / \mathrm{kg} /$ day, demonstrate increased intestinal postprandial perfusion while cerebral perfusion remains stable [2, 15-17]. Nevertheless, little is known about whether this capability of the premature intestine to increase its perfusion after feeding is dependent on postnatal age (PNA), postmenstrual age (PMA), and/or feeding volumes. In addition, it remains unclear if cerebral perfusion also remains stable when postprandial redistribution of blood in favour of the intestines occurs soon after birth or in younger infants. Furthermore, studies that evaluated whether the presence or absence of postprandial intestinal hyperaemia is associated with the development of FI or with the development of NEC, are limited. Therefore our aim was to determine the effect of enteral bolus feeding on intestinal oxygen saturation $\left(\mathrm{r}_{\text {int }} \mathrm{SO}_{2}\right)$ and extraction in preterm infants during the first five weeks after birth, and to evaluate whether this effect depended on PNA, PMA, and/or feeding volumes. Furthermore, we explored whether the cerebral oxygen saturation $\left(\mathrm{r}_{\mathrm{C}} \mathrm{SO}_{2}\right)$ and extraction changed when postprandial $\mathrm{r}_{\mathrm{int}} \mathrm{SO}_{2}$ increased after enteral feeding.

\section{Methods}

\section{Participants}

For this prospective, longitudinal, observational, exploratory study we derived patients from a larger observational cohort study at our tertiary referral neonatal intensive care unit (NICU) that aimed to identify prognostic markers for the development of NEC in high-risk neonates (CALIFORNIA-Trial, Dutch Trial Registry NTR4153) $[18,19]$. For this trial, all infants who were at high risk of developing NEC, who were born between October 2012 and February 2014, and had been admitted to our NICU were eligible for inclusion. High-risk infants were defined as infants with a gestational age (GA) of less than 30 weeks or a birth weight (BW) of less than $1000 \mathrm{~g}$, or a GA of less than 32 weeks and a BW below $1200 \mathrm{~g}$, or preterm-born infants who had been exposed to indomethacin antenatally [20]. Exclusion criteria were congenital abdominal malformations or large chromosomal defects. For this pilot sub-study, which was part of a new scientific project, we started with precisely recording the feeding times from August 2013 onwards and included all preterm infants born between August 2013 and January 2014 and who had been admitted to our NICU. All infants were included after their parents had given written informed consent within $72 \mathrm{~h}$ after birth. The study was approved by the ethical review board of University Medical Center Groningen.

\section{Feeding data}

All infants received enteral feeding through nasogastric tubes. Feedings consisted of preterm formula, mother's own milk, donor mother's milk, or a combination. Infants who weighed less than $1200 \mathrm{~g}$ received enteral bolus feeding every two hours for 10 to $15 \mathrm{~min}$ by tube and open syringe using gravity. Infants who weighed more than $1200 \mathrm{~g}$ were fed once every three hours. As feeding volumes are relatively larger in case of bolus feeding once every three hours than once every two hours, we recorded feeding volumes in $\mathrm{mL} / \mathrm{kg} /$ day but also in $\mathrm{mL} / \mathrm{kg}$ during the NIRS measurement. All infants received 10 to $20 \mathrm{~mL} / \mathrm{kg}$ on the first day after birth. Subsequently, feeding volumes were increased daily by 20 $\mathrm{mL} / \mathrm{kg} /$ day unless gastrointestinal problems, such as recurrent vomiting or gastric retentions exceeding $5 \mathrm{~mL}$, occurred repeatedly.

The feeding times were recorded during the NIRS measurements. We recorded the time at which feeding commenced, that is the time the feeding bolus was connected to the feeding tube, and the time feeding ended, that is the time the feeding tube was empty, feeding volumes (expressed in $\mathrm{mL}$ ), and the type of feeding received by the infant.

\section{Gastrointestinal complications}

We recorded whether infants developed FI, NEC or a spontaneous intestinal (SIP) perforation. FI was defined as $>50 \%$ decrease in $\mathrm{ml} / \mathrm{kg} /$ day of enteral feeding or withdrawal of enteral feeding because of abdominal 
distension, vomiting, abundant gastric retentions, bilious or bloody gastric retentions, or bloody stools.

\section{Clinical characteristics}

Prospectively, we collected data on GA, BW, PMA, PNA, sex, Apgar scores, SNAPPE-II score as measure for severity of illness [21], respiratory support, $\mathrm{PCO}_{2}$, $\mathrm{pH}$, haemoglobin, systolic, diastolic, and mean arterial blood pressure, the need for fluid resuscitation or inotropic support, the presence of a hemodynamically significant patent ductus arteriosus (PDA), and the presence of cerebral pathologies on cerebral ultrasound.

\section{Near-infrared spectroscopy}

We used the INVOS 5100C near-infrared spectrometer in combination with neonatal SomaSensors (Medtronic, Dublin, Ireland) to measure $\mathrm{r}_{\mathrm{int}} \mathrm{SO}_{2}$ and $\mathrm{r}_{\mathrm{c}} \mathrm{SO}_{2}$. We used Mepitel $^{\bullet}$ film (Mölnlycke, Sweden), which does not adversely affect INVOS integrity or validity [22], to keep the sensor in place and as a skin barrier below each sensor. To measure $\mathrm{r}_{\mathrm{int}} \mathrm{SO}_{2}$ we placed the sensor infraumbilically on the central abdomen. To measure $\mathrm{r}_{\mathrm{c}} \mathrm{SO}_{2}$ we placed the sensor on the left or right frontoparietal side of the head. Intestinal and cerebral $\mathrm{rSO}_{2}$ were measured for two uninterrupted hours, starting at $5 \mathrm{~min}$ prior to feeding, during postnatal Days 2 to $5,8,15,22,29$, and 36. The study ended prior to Day 36 if an infant developed NEC Bell Stage $\geq 2$, died, or was discharged from the NICU. We removed artefacts from the $\mathrm{rSO}_{2}$ measurements. Artefacts were defined as instances recorded as sensor displacement, or a sudden major nonphysiologic increase or decrease of the $\mathrm{rSO}_{2}$ values within seconds, which suggests an incorrect measurement. We measured transcutaneous arterial oxygen saturation $\left(\mathrm{SpO}_{2}\right)$ simultaneously with the $\mathrm{rSO}_{2}$ measurements using Nellcor (Medtronic) sensors. Next, we calculated intestinal and cerebral FTOE with the following formula: $\left(\mathrm{SpO}_{2}-\mathrm{rSO}_{2}\right) / \mathrm{SpO}_{2}$. The FTOE reflects the balance between oxygen delivery to the tissue measured and oxygen consumption of the tissue measured, and depends less on changes in arterial oxygen saturation [10].

\section{Statistical analyses and sample size}

For statistical analyses we used SPSS 23.0 (IBM Corp., Armonk, NY, USA). We described the patient characteristics in terms of median (range) values. First, after confirming normal distribution of the data, we calculated the mean and standard error of the mean (SE) of all NIRS measurements at three points in time on postnatal Days 2 to $5,8,15,22,29$, and 36 , viz. 5 min prior to feeding and 10 to $30 \mathrm{~min}$ and 30 to $60 \mathrm{~min}$ after feeding had commenced. SE was preferred over standard deviation, given the comparison of means and given the small sample size, which may hamper accurate estimation of the means [23, 24]. Next, we built a multilevel model for each dependent variable using the statistical program MLwiN 2.15 (University of Bristol, Bristol, UK) [25]. Given the presence of missing data, an advantage of multilevel analysis is that this analysis calculates weighted means and their standard errors, which takes the number of data points per infant into account, thus allowing infants with more data points to weigh more into the estimated mean than infants with less data points. Four models, one for each dependent variable $\left(\mathrm{r}_{\text {int }} \mathrm{SO}_{2}, \mathrm{r}_{\mathrm{c}} \mathrm{SO}_{2}\right.$, intFTOE, and cFTOE) were specified with measurements (Level 1) nested within subjects (Level 2). Thus, the dependency between measurements was taken into consideration in which the intercept represented the baseline measurement (before feeding) on Day 2. To compare preprandial measurements with measurements 10 to 30 and 30 to 60 min postprandially, each model consisted of 27 terms ( 9 days multiplied by the three points in time; that is each term is defined as one measurement of one day). A $t$ test was used to test for differences between an estimated mean and the intercept [26]. We tested the contrast of the sum of parameters from which each estimate is derived using a chi-square test with one degree of freedom to test for differences between two estimated means.

Second, to evaluate whether the effect of enteral bolus feeding on the $\mathrm{r}_{\mathrm{int}} \mathrm{SO}_{2}$ depended on PMA, we clustered the measurements into different groups, that is PMA < or $\geq 30$ weeks and $<$ or $\geq 32$ weeks and performed a Wilcoxon signed rank test between preprandial and postprandial $\mathrm{r}_{\text {int }} \mathrm{SO}_{2}$ values. Next, to determine whether feeding volumes were associated with the effect of enteral feeding on $\mathrm{r}_{\mathrm{int}} \mathrm{SO}_{2}$, we used a univariate logistics regression analysis between postprandial $\mathrm{r}_{\mathrm{int}} \mathrm{SO}_{2}$ values (categorized into increase or no increase) and the amount of the bolus enteral feeding per $10 \mathrm{~mL} / \mathrm{kg}$.

Thereafter, to explore whether a postprandial $\mathrm{r}_{\mathrm{int}} \mathrm{SO}_{2}$ increase was associated with a decreased postprandial $\mathrm{r}_{\mathrm{c}} \mathrm{SO}_{2}$, we performed a logistic regression analysis between categorized data; that is increase or no increase of the $\mathrm{r}_{\mathrm{int}} \mathrm{SO}_{2}$ versus decrease or no decrease of the $\mathrm{r}_{\mathrm{c}} \mathrm{SO}_{2}$. Finally, we performed a subanalysis between infants who did and did not develop any GI complications. Infants were categorized into four groups; Uncomplicated, FI, NEC, and SIP. As two out of the three NEC infants developed NEC within 14 days, we clustered the data from the first two postnatal weeks and calculated delta's between baseline $\mathrm{r}_{\text {int }} \mathrm{SO}_{2}$ and postprandial $\mathrm{r}_{\mathrm{int}} \mathrm{SO}_{2}$ values, and performed a Mann Whitney $\mathrm{U}$ between delta's of the infants with and without a GI complication. For this subanalysis, we used a nonparametric test as the delta's in this small sample size were not normally distributed and therefore presented these data in medians [IQRs]. 
Throughout the analyses a $P$ value $<.05$ was considered statistically significant. We chose not to correct for multiple testing in this explorative study.

\section{Results}

\section{Patient characteristics}

We included 29 patients out of 33 eligible patients (Fig. 1). We had to exclude four infants because of missing $\mathrm{rSO}_{2}$ data. The 29 remaining infants had a median GA of 28.1 weeks (range 25.1-30.7) and a median BW of $1025 \mathrm{~g}$ (range 580-1495). Table 1 provides an overview of the patient characteristics. Three infants died during the study period after a median of 21 days (range 16-25) after birth: one infant died of NEC, one of multi-organ failure as a result of sepsis, and one infant died of progressive respiratory failure. Three infants developed NEC Bell's Stage $\geq 2$ on postnatal Days 7, 10, and 30, respectively. Two infants developed a spontaneous intestinal perforation on postnatal Day 8 and Day 12. Thirteen patients were discharged from the NICU prior to the 36th day (from Day 15 onward). In 16 patients we were unable to measure intestinal NIRS during the first two to eight days after birth because of the placement of umbilical catheters taped to the infraumbilical skin or as a result of a lack of space on the infants' abdomens.

\section{The effect of feeding on intestinal oxygenation in relation to postnatal age}

On Day 5, mean postprandial $\mathrm{r}_{\text {int }} \mathrm{SO}_{2}$ values were lower than mean preprandial values: 10 to $30 \mathrm{~min}$ after feeding $\mathrm{r}_{\text {int }} \mathrm{SO}_{2}$ was $38 \%$ (SE 7) versus $44 \%$ (SE 10) before feeding, just failing to reach significance $(n=12, P=.07)$, while 30 to $60 \mathrm{~min}$ after feeding the decrease was significant $(35 \%$, SE 7, versus $44 \%$, SE $10, \mathrm{n}=12, P=.01$ ). On Day 29 (median postmenstrual age: 31.7 weeks, range 29.3-34.7), mean postprandial $\mathrm{r}_{\mathrm{int}} \mathrm{SO}_{2}$ values 10 to $30 \mathrm{~min}$ after feeding increased with respect to preprandial values $\left(r_{\text {int }} \mathrm{SO}_{2}\right.$ $54 \%$, SE 7 , versus $44 \%$, SE $11, n=10, P=.01)$. The intFTOE did not change concomitantly. We provide a complete overview of the results in Table 2 and Fig. 2.

\section{The effect of feeding on $\mathrm{r}_{\mathrm{int}} \mathrm{SO}_{2}$ in relation to postmenstrual age}

We found that infants with a PMA $\geq 32$ weeks showed a significant postprandial increase of the $\mathrm{r}_{\text {int }} \mathrm{SO}_{2} 10$ to 30

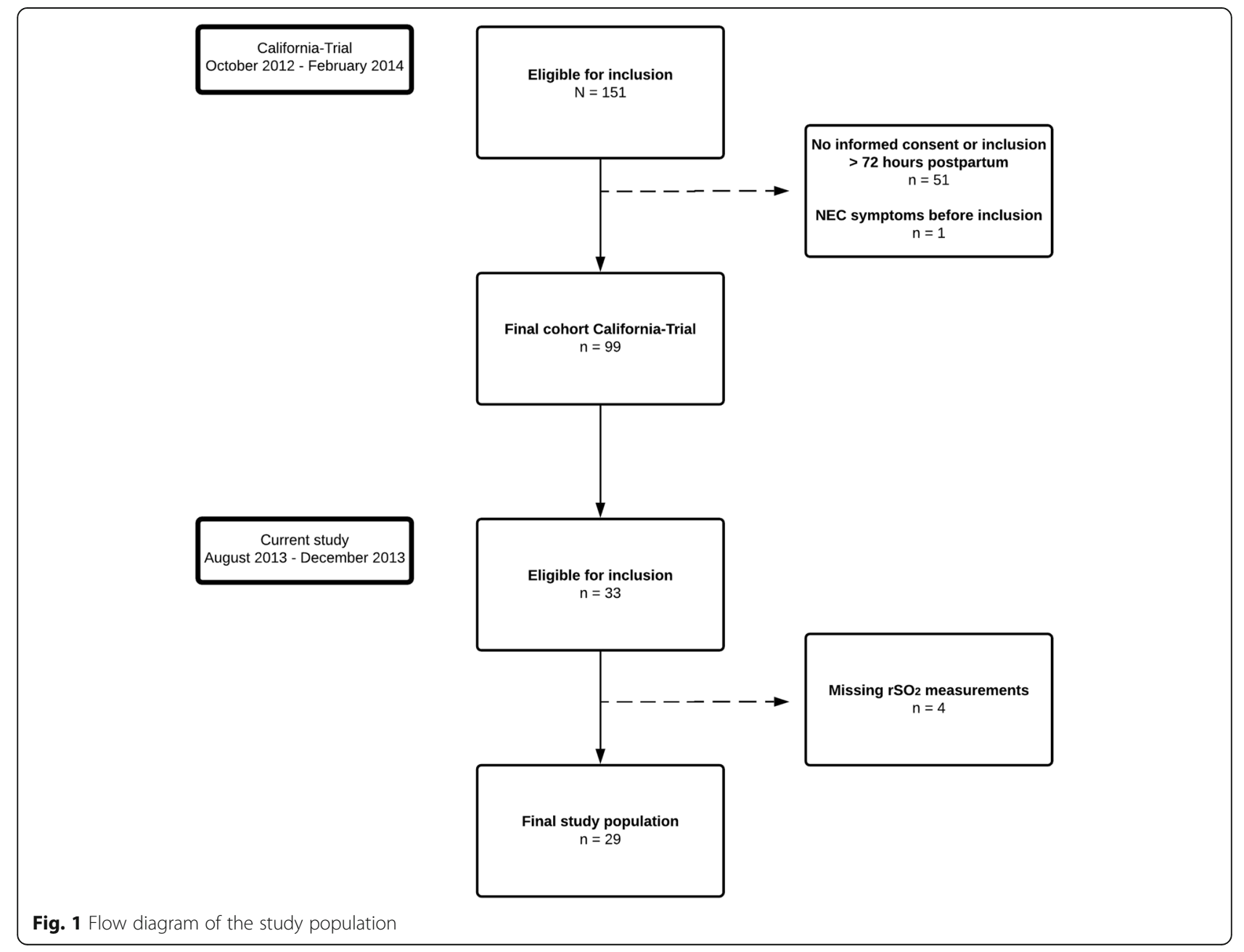


Table 1 Patient characteristics during the study period

\begin{tabular}{ll}
\hline Study population & $n=29$ \\
\hline Boys/Girls & $16 / 13(65 \% / 45 \%)$ \\
Gestational age, weeks & $28+1(25+1-30+5)$ \\
Birth weight, g & $1025(580-1495)$ \\
Sets of twins & $4(14 \%)$ \\
Small-for-gestational-age $(P<10)$ & $6(21 \%)$ \\
Head circumference on day of birth, & $25.0(22.5-29.0)$ \\
centimetres & \\
Apgar score at 5 min & $7(2-9)$ \\
SNAPPE-ll score & $28(0-77)$ \\
Intestinal pathologies & \\
Necrotizing enterocolitis/spontaneous & $4(14 \%)$ \\
intestinal perforation & $22(76 \%)$ \\
Sepsis (including suspected sepsis) & \\
Circulatory failure & $7(24 \%)$ \\
Fluid resuscitation & $2(7 \%)$ \\
Inotropic treatment & \\
Respiratory support & \\
Mechanical ventilation & $16(55 \%)$ \\
Continuous positive airway pressure & $27(93 \%)$ \\
High flow & $7(24 \%)$ \\
Low flow or no support & $15(52 \%)$
\end{tabular}

Cerebral lesions

Germinal matrix haemorrhage-intraventricular haemorrhage

$\begin{array}{ll}\text { Grade I } & 6(21 \%) \\ \text { Grade II } & 2(7 \%) \\ \text { Transient periventricular echodensities } & 10(34 \%) \\ \text { Periventricular leukomalacia } & 13(45 \%) \\ \text { Patent ductus arteriosus } & \\ \text { Expectative policy } & 7(24 \%) \\ \text { Ibuprofen treatment } & 6(21 \%) \\ \text { Surgical clip } & 3(10 \%) \\ \text { Hyperbilirubinemia } & 23(79 \%) \\ \text { Anaemia } & 19(66 \%)\end{array}$

Hemoglobin ( $\mathrm{mmol} / \mathrm{L})$

Day 2

$9.1(7.6-11.6)$

Day 3

Day 4

Day 5

Day 8

Day 15

Day 22

Day 29

Day 36

Enteral feeding ${ }^{a}$

Mother's milk
Table 1 Patient characteristics during the study period

(Continued)

\begin{tabular}{ll}
\hline Study population & $n=29$ \\
\hline Preterm formula & $20(69 \%)$ \\
Donor mother's milk & $10(34 \%)$ \\
Infusion rate bolus feeding (mL/min) & $3.4(0.1-60.0)$
\end{tabular}

Abbreviations: SD, standard deviation. SNAPPE-II, Score for Neonatal Acute Physiology - Perinatal Extension II. The data are expressed as median (range) or as numbers (percentages) unless otherwise specified. ${ }^{\text {TT }}$ The numbers exceed totals, because a single infant could have several respiratory supports and several types of enteral feeding during the first 36 days after birth

min after feeding (37\% versus 51\%, $P=.04, \mathrm{n}=10,13$ measurements) and a non-significant increase 30 to 60 min after feeding (37\% versus 44\%, $P=.06, n=10,13$ measurements). All data are presented in Fig. 3.

\section{The effect of enteral bolus feeding on $\mathrm{r}_{\mathrm{int}} \mathrm{SO}_{2}$ in relation to feeding volumes}

We found a significant association between feeding volumes $(\mathrm{mL} / \mathrm{kg})$ and the change in $\mathrm{r}_{\mathrm{int}} \mathrm{SO}_{2} 10$ to $30 \mathrm{~min}$ after feeding. For every $10 \mathrm{~mL} / \mathrm{kg}$ more enteral feeding per bolus 10 to $30 \mathrm{~min}$ after feeding, the odds score for an increasing postprandial $\mathrm{r}_{\text {int }} \mathrm{SO}_{2}$ was 1.6 times higher (95\% CI, 1.02-2.59, $P=.04$ ). Feeding volumes were not significantly associated with the change in $\mathrm{r}_{\text {int }} \mathrm{SO}_{2} 30$ to 60 min after feeding. Table 3 provides an overview of enteral feeding volumes.

\section{The effect of a changing intestinal oxygenation after feeding on cerebral oxygenation}

Clustering all feeds observed, for all instances that the postprandial $\mathrm{r}_{\mathrm{int}} \mathrm{SO}_{2}$ increased, the median postprandial increase was $7 \%$ (range $1-41, n=21,42$ measurements) 10 to $30 \mathrm{~min}$ and $11 \%$ (range $1-41, n=22,40$ measurements) 30 to $60 \mathrm{~min}$ after feeding, respectively. For all instances that the postprandial $\mathrm{r}_{\mathrm{c}} \mathrm{SO}_{2}$ decreased, median postprandial decrease was $-5 \%$ (range -22 to $-1, n=$ 29, 77 measurements) 10 to $30 \mathrm{~min}$ and $-4 \%$ (range -31 to $-1, \mathrm{n}=29,82$ measurements) 30 to $60 \mathrm{~min}$ after feeding, respectively. We did not find an association between an increasing postprandial $\mathrm{r}_{\mathrm{int}} \mathrm{SO}_{2}$ and a decreasing postprandial $\mathrm{r}_{\mathrm{c}} \mathrm{SO}_{2}$. We did, however, find that the absence of an increasing postprandial $\mathrm{r}_{\mathrm{int}} \mathrm{SO}_{2}$ was significantly associated with a 3.6 times higher odds ratio for a decreasing $\mathrm{r}_{\mathrm{c}} \mathrm{SO}_{2} 10$ to $30 \mathrm{~min}(95 \% \mathrm{CI}, 1.5-8.9, P=<.01)$ and a 3.0 times higher odds ratio for a decreasing $\mathrm{r}_{\mathrm{C}} \mathrm{SO}_{2} 30$ to 60 min (95\% CI, 1.2-7.3, $P=.02$ ) after feeding. Preprandial and postprandial $\mathrm{r}_{\mathrm{c}} \mathrm{SO}_{2}$ (and cFTOE) values are presented in Table 2.

\section{Infants with and without the development of gastrointestinal complications}

Seven infants developed FI (24\%), three infants developed NEC (10\%), and two (7\%) infants developed SIP. 
Table 2 Preprandial compared to postprandial values of $r_{\text {int }} \mathrm{SO}_{2}, \mathrm{r}_{\mathrm{c}} \mathrm{SO}_{2}$, intFTOE, and $\mathrm{CFTOE}$ values on postnatal days

\begin{tabular}{|c|c|c|c|c|c|}
\hline & M1 Mean (SE) & M2 Mean (SE) & M3 Mean (SE) & $P$ value M1 vs. M2 & $P$ value $\mathrm{M} 1$ vs. M3 \\
\hline \multicolumn{6}{|l|}{ Day 2} \\
\hline$r_{\text {int }} \mathrm{SO}_{2}(\%, n=10)$ & $40(11)$ & $38(7)$ & $40(7)$ & .46 & 1.00 \\
\hline$r_{c} \mathrm{SO}_{2}(\%, n=28)$ & $77(4)$ & 77 (3) & 78 (3) & .71 & .43 \\
\hline intFTOE $(n=9)$ & $0.48(0.14)$ & $0.57(0.14)$ & $0.47(0.14)$ & .24 & .85 \\
\hline cFTOE $(n=27)$ & $0.13(0.04)$ & $0.14(0.04)$ & $0.13(0.04)$ & .97 & .90 \\
\hline \multicolumn{6}{|l|}{ Day 3} \\
\hline $\mathrm{r}_{\mathrm{int}} \mathrm{SO}_{2}(\%, n=7)$ & $37(11)$ & $39(7)$ & $41(7)$ & .58 & .32 \\
\hline$r_{c} \mathrm{SO}_{2}(\%, n=25)$ & $75(4)$ & $76(3)$ & $76(3)$ & .30 & .37 \\
\hline intFTOE $(n=7)$ & $0.58(0.14)$ & $0.48(0.14)$ & $0.51(0.14)$ & .18 & .31 \\
\hline cFTOE $(n=25)$ & $0.17(0.04)$ & $0.17(0.04)$ & $0.16(0.04)$ & .80 & .46 \\
\hline \multicolumn{6}{|l|}{ Day 4} \\
\hline$r_{\text {int }} \mathrm{SO}_{2}(\%, n=11)$ & $34(10)$ & $34(7)$ & $35(7)$ & .91 & .59 \\
\hline$r_{c} \mathrm{SO}_{2}(\%, n=28)$ & $73(4)$ & $72(3)$ & $73(3)$ & .48 & .83 \\
\hline $\operatorname{intFTOE~}(n=11)$ & $0.65(0.14)$ & $0.59(0.14)$ & $0.57(0.14)$ & .34 & .19 \\
\hline cFTOE $(n=28)$ & $0.18(0.04)$ & $0.20(0.04)$ & $0.17(0.04)$ & .27 & .67 \\
\hline \multicolumn{6}{|l|}{ Day 5} \\
\hline $\mathrm{r}_{\mathrm{int}} \mathrm{SO}_{2}(\%, n=12)$ & $44(10)$ & $38(7)$ & $35(7)$ & .07 & $.01^{*}$ \\
\hline$r_{c} \mathrm{SO}_{2}(\%, n=27)$ & $73(4)$ & $72(3)$ & $72(3)$ & .32 & .19 \\
\hline $\operatorname{intFTOE~}(n=12)$ & $0.49(0.14)$ & $0.58(0.14)$ & $0.48(0.14)$ & .16 & .84 \\
\hline cFTOE $(n=27)$ & $0.19(0.04)$ & $0.21(0.04)$ & $0.21(0.04)$ & .26 & .27 \\
\hline \multicolumn{6}{|l|}{ Day 8} \\
\hline$r_{\text {int }} \mathrm{SO}_{2}(\%, n=12)$ & $39(10)$ & $38(7)$ & $35(7)$ & .61 & .21 \\
\hline$r_{c} \mathrm{SO}_{2}(\%, n=25)$ & $67(4)$ & $71(3)$ & $73(3)$ & $.01^{*}$ & $\leq .01^{*}$ \\
\hline $\operatorname{intFTOE~}(n=12)$ & $0.59(0.13)$ & $0.56(0.13)$ & $0.62(0.14)$ & .63 & .66 \\
\hline cFTOE $(n=25)$ & $0.25(0.04)$ & $0.22(0.04)$ & $0.20(0.04)$ & .27 & $.03^{*}$ \\
\hline \multicolumn{6}{|l|}{ Day 15} \\
\hline$r_{\text {int }} \mathrm{SO}_{2}(\%, n=15)$ & $34(10)$ & $39(7)$ & $38(7)$ & .13 & .15 \\
\hline$r_{c} \mathrm{SO}_{2}(\%, n=19)$ & $66(4)$ & $64(3)$ & $63(3)$ & .22 & .09 \\
\hline intFTOE $(n=15)$ & $0.59(0.13)$ & $0.51(0.13)$ & $0.58(0.13)$ & .17 & .87 \\
\hline cFTOE $(n=19)$ & $0.28(0.05)$ & $0.26(0.04)$ & $0.27(0.04)$ & .33 & .76 \\
\hline \multicolumn{6}{|l|}{ Day 22} \\
\hline $\mathrm{r}_{\mathrm{int}} \mathrm{SO}_{2}(\%, \mathrm{n}=11)$ & $48(10)$ & $47(7)$ & $45(7)$ & .67 & .35 \\
\hline$r_{c} \mathrm{SO}_{2}(\%, n=14)$ & $57(4)$ & $58(3)$ & $58(3)$ & .46 & .39 \\
\hline $\operatorname{intFTOE~}(n=11)$ & $0.46(0.14)$ & $0.45(0.14)$ & $0.46(0.14)$ & .93 & .90 \\
\hline cFTOE $(n=14)$ & $0.36(0.05)$ & $0.27(0.05)$ & $0.33(0.04)$ & $\leq .01^{*}$ & .23 \\
\hline \multicolumn{6}{|l|}{ Day 29} \\
\hline $\mathrm{r}_{\mathrm{int}} \mathrm{SO}_{2}(\%, \mathrm{n}=10)$ & $44(11)$ & $54(7)$ & $50(7)$ & $.01^{*}$ & .18 \\
\hline$r_{c} \mathrm{SO}_{2}(\%, n=12)$ & $62(5)$ & $63(3)$ & $62(3)$ & .63 & .87 \\
\hline intFTOE $(n=10)$ & $0.43(0.14)$ & $0.40(0.14)$ & $0.45(0.14)$ & .65 & .78 \\
\hline CFTOE $(n=12)$ & $0.26(0.05)$ & $0.27(0.05)$ & $0.28(0.05)$ & .71 & .42 \\
\hline \multicolumn{6}{|l|}{ Day 36} \\
\hline$r_{i n t} \mathrm{SO}_{2}(\%, n=8)$ & $47(11)$ & $49(7)$ & $46(7)$ & .56 & .84 \\
\hline $\mathrm{r}_{\mathrm{C}} \mathrm{SO}_{2}(\%, \mathrm{n}=8)$ & $65(5)$ & 65 (3) & $66(3)$ & .80 & .52 \\
\hline intFTOE ( $n=8)$ & $0.40(0.14)$ & $0.37(0.14)$ & $0.50(0.14)$ & .65 & .21 \\
\hline CFTOE $(n=8)$ & $0.26(0.05)$ & $0.26(0.05)$ & $0.23(0.05)$ & .88 & .37 \\
\hline
\end{tabular}

Abbreviations: M1 Measurement 1 (preprandial), M2 Measurement 2 (10 to 30 min postprandial), M3 Measurement 3 (30 to 60 min postprandial). The data are expressed as mean (standard errors of the mean) unless otherwise specified. ${ }^{*}=P$ value $<.05$ 


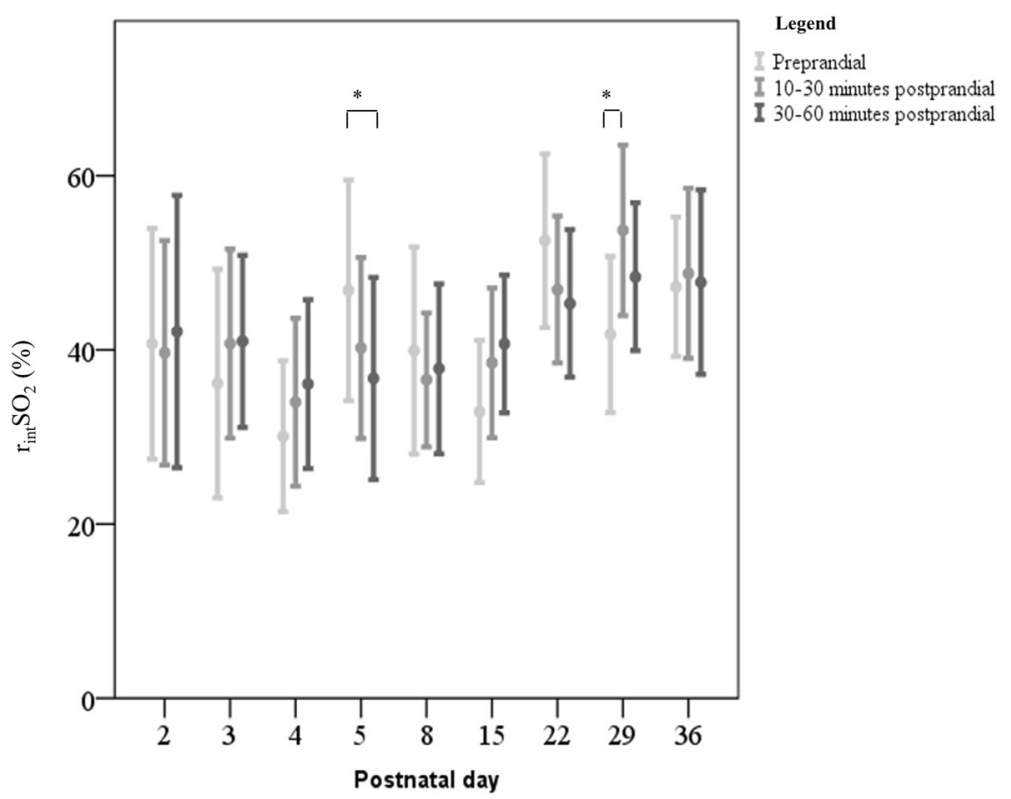

Fig. 2 Preprandial $r_{\text {int }} \mathrm{SO}_{2}$ values compared to postprandial $r_{\text {int }} \mathrm{SO}_{2}$ values on postnatal days The bars represent the mean and standard error of the mean of individual $r_{\text {int }} \mathrm{SO}_{2}$ values before and after enteral feeding. The mean $\mathrm{r}_{\text {int }} \mathrm{SO}_{2}$ is marked with a o within the bars. Statistically significant differences are marked with an asterisk: ${ }^{*}<.05$

We did not find a change in $\mathrm{r}_{\text {int }} \mathrm{SO}_{2}$ 10-30 min after feeding between infants who developed NEC and infants who did not develop a GI complication during the first two postnatal weeks. The infants who developed NEC, however, tended to have a decreasing $\mathrm{r}_{\mathrm{int}} \mathrm{SO}_{2} 30-60 \mathrm{~min}$ after enteral feeding compared to infants without GI complications ( $-24 \%$ vs. $1 \%, P=.06)$ during the first two postnatal weeks (Fig. 4). There was no change in $\mathrm{r}_{\text {int }} \mathrm{SO}_{2}$ 10-30 min and 30-60 min after feeding between infants who developed FI and infant without GI complications, and between infants who developed SIP and infants without GI complications (Fig. 4).

\section{Discussion}

We demonstrated that in our group of preterm infants, born after approximately 28 weeks of gestation, a postprandial increase of intestinal oxygen saturation does occur, albeit at group level only in the fifth week after birth or in infants of a relatively older corrected gestational age. Furthermore, we showed that not a postprandial increase of intestinal oxygenation, but rather the absence thereof, was associated with a higher risk of a decrease of the cerebral oxygen saturation.

Our results suggest that during the first four weeks after birth at group level, intestinal perfusion does not exceed any potential increased oxygen consumption after enteral feeding. In the fifth week after birth the PMA of the remaining infants was 31.7 weeks. We assume that during this period the postprandial effect of feeding on the intestinal $\mathrm{rSO}_{2}$ can be explained by an increasing PMA rather than PNA, because we demonstrated that infants with a PMA $\geq 32$ weeks have an increased postprandial $\mathrm{r}_{\mathrm{int}} \mathrm{SO}_{2}$. In addition, by this time the remaining infants received relatively greater feeding volumes, which we demonstrated to be another important factor to elicit postprandial hyperaemia. Previous reports showed increased postprandial intestinal oxygen saturation using NIRS $[2,15,16]$ or increased postprandial blood flow velocity of the SMA using Doppler measurements [3, 4], but these measurements were mainly done cross-sectionally, in fullterm and preterm infants with a corrected GA of at least 32 weeks, and were not assessed from birth onwards.

We offer several explanations for the fact that we did not find increased intestinal oxygen saturation after enteral bolus feeding during the first four weeks after birth and in the younger infants with a PMA $<32$ weeks based on the principle that intestinal oxygenation consists of a balance between oxygen supply and consumption [15]. First, it may be that neither intestinal oxygen supply nor oxygen consumption changes in very preterm infants after enteral feeding because of intestinal immaturity on account of the fact that intestinal maturation is an ongoing process up to 33 to 34 weeks of gestation, and even beyond [27].

Besides intestinal immaturity, the low feeding volumes received during the first weeks after birth, especially in the youngest infants, may only result in a limited increase of intestinal metabolism and perfusion. Previous reports on animal models demonstrated a dose- 


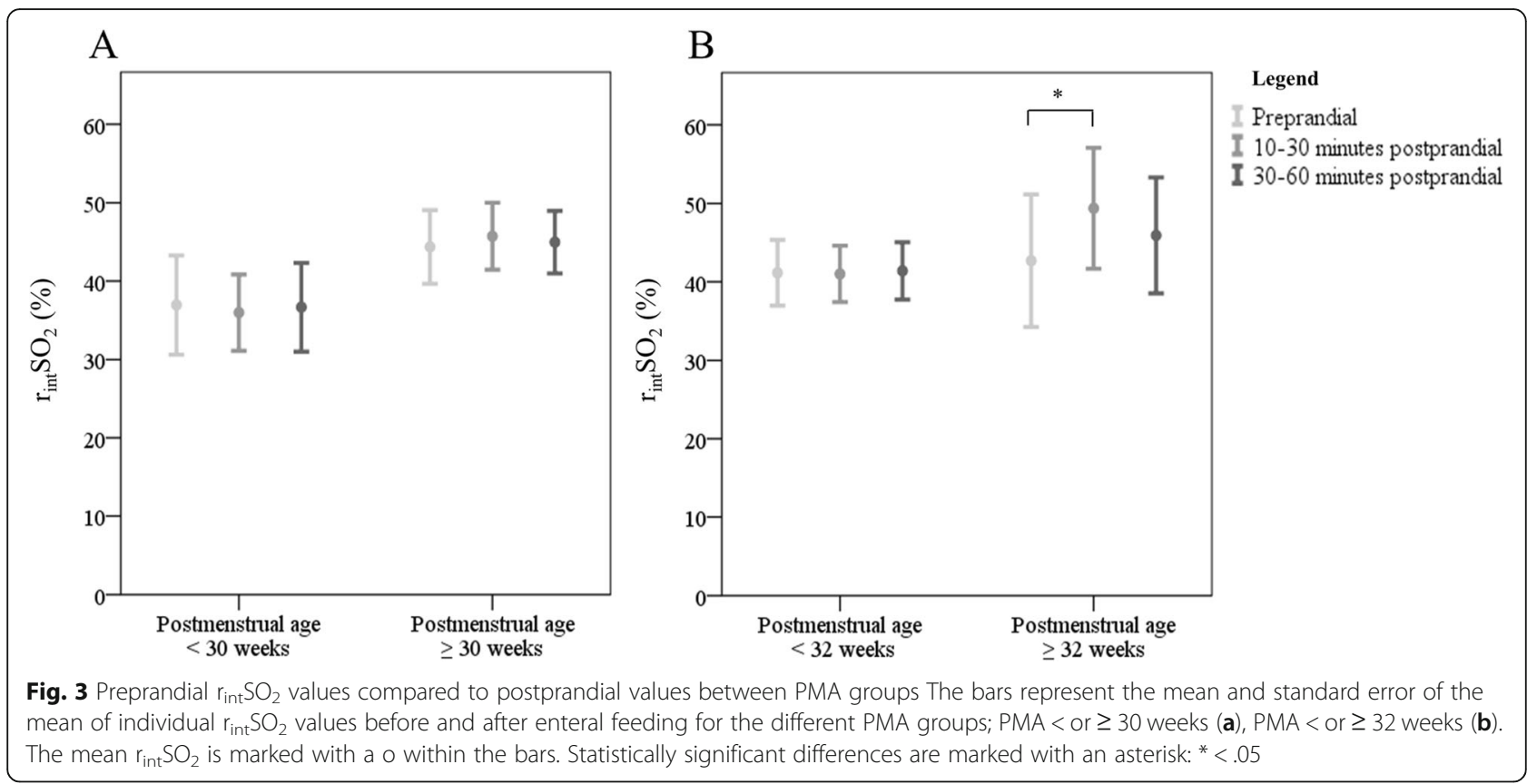

dependent hyperaemic intestinal response after feeding [28, 29]. In addition, previous studies that reported increased intestinal perfusion after feeding were performed in preterm infants who tolerated feeding volumes of 100 $\mathrm{mL} / \mathrm{kg} /$ day $[2,15-17]$. We confirmed that indeed increased feeding volumes were associated with a higher chance of increasing intestinal saturation after feeding.

Another, but perhaps less likely explanation for not finding any change in intestinal oxygenation after feeding in the youngest infants, may come from a potentially perfect balance between oxygen supply and oxygen consumption. It may be that both increase equally after enteral feeding. One would, however, sooner expect such perfect harmony in the more mature infants.

Finally, several perinatal conditions may have influenced our findings. In comparison to populations reported on

Table 3 Enteral feeding volumes of all included infants per day and during NIRS measurement

\begin{tabular}{lll}
\hline Day & Feeding $\mathrm{mL} / \mathrm{kg} /$ day & Feeding $\mathrm{mL} / \mathrm{kg} /$ measurement \\
\hline $2(\mathrm{n}=29)$ & $20.8(17.8-26.7)$ & $2.1(1.4-2.7)$ \\
$3(\mathrm{n}=29)$ & $39.4(27.9-43.3)$ & $2.8(2.3-4.1)$ \\
$4(\mathrm{n}=29)$ & $56.3(34.5-63.2)$ & $4.4(3.2-6.2)$ \\
$5(n=29)$ & $73.1(44.5-80.9)$ & $5.6(3.9-7.8)$ \\
$8(n=27)$ & $101.2(68.1-125.7)$ & $8.9(5.3-12.7)$ \\
$15(n=23)$ & $149.3(88.8-152.3)$ & $12.4(8.7-13.3)$ \\
$22(n=17)$ & $150.1(139.8-156.2)$ & $14.0(12.2-19.0)$ \\
$29(n=12)$ & $145.4(127.7-153.2)$ & $17.2(11.9-18.6)$ \\
$36(n=10)$ & $149.5(125.7-154.1)$ & $18.4(14.8-19.1)$ \\
\hline
\end{tabular}

The data are expressed as median (interquartile range) previously, our study population consisted of a relatively large proportion of infants who had a hemodynamically significant PDA. It has been demonstrated that preterm infants with large PDAs show a very slight increase of SMA blood flow velocities one hour after enteral bolus feeding compared to preterm infants without a PDA or a small or moderate PDA [30]. Therefore, in our study, the relative large proportion of infants with a PDA might have contributed to a lack of postprandial $\mathrm{r}_{\mathrm{int}} \mathrm{SO}_{2}$ increase at group level. Additionally, other perinatal morbidities, (that is being born small for gestational age or anaemia, Table 1) may also have contributed to our results. Two recent studies demonstrated a lack of increase, or even a decrease, in postprandial $\mathrm{r}_{\mathrm{int}} \mathrm{SO}_{2}$ in a group of anaemic preterm infants and in preterm infants who showed fetal signs of intrauterine growth restriction [31, 32]. Martini et al. showed that preterm infants with abnormal prenatal umbilical Doppler measurements lack any effect of the first enteral feeding on $\mathrm{r}_{\text {int }} \mathrm{SO}_{2}$ [29]. The results of these studies suggest that the intestinal response to enteral feeds is complex and that it is influenced by intestinal immaturity as well as intestinal condition and other perinatal factors [31, 32]. The hemoglobin levels in our study population decreased over time during the five weeks after birth, while we demonstrated that the $\mathrm{r}_{\text {int }} \mathrm{SO}_{2}$ increased after enteral feeding in the fifth week after birth. We therefore speculate that the maturing process of the intestine after birth and the greater feeding volumes have a larger contribution on the change in intestinal oxygen saturation after enteral feeding and attenuate the effect of the level of hemoglobin. Unfortunately, we were unable to perform subanalyses to address these issues on account of the size of our sample. 


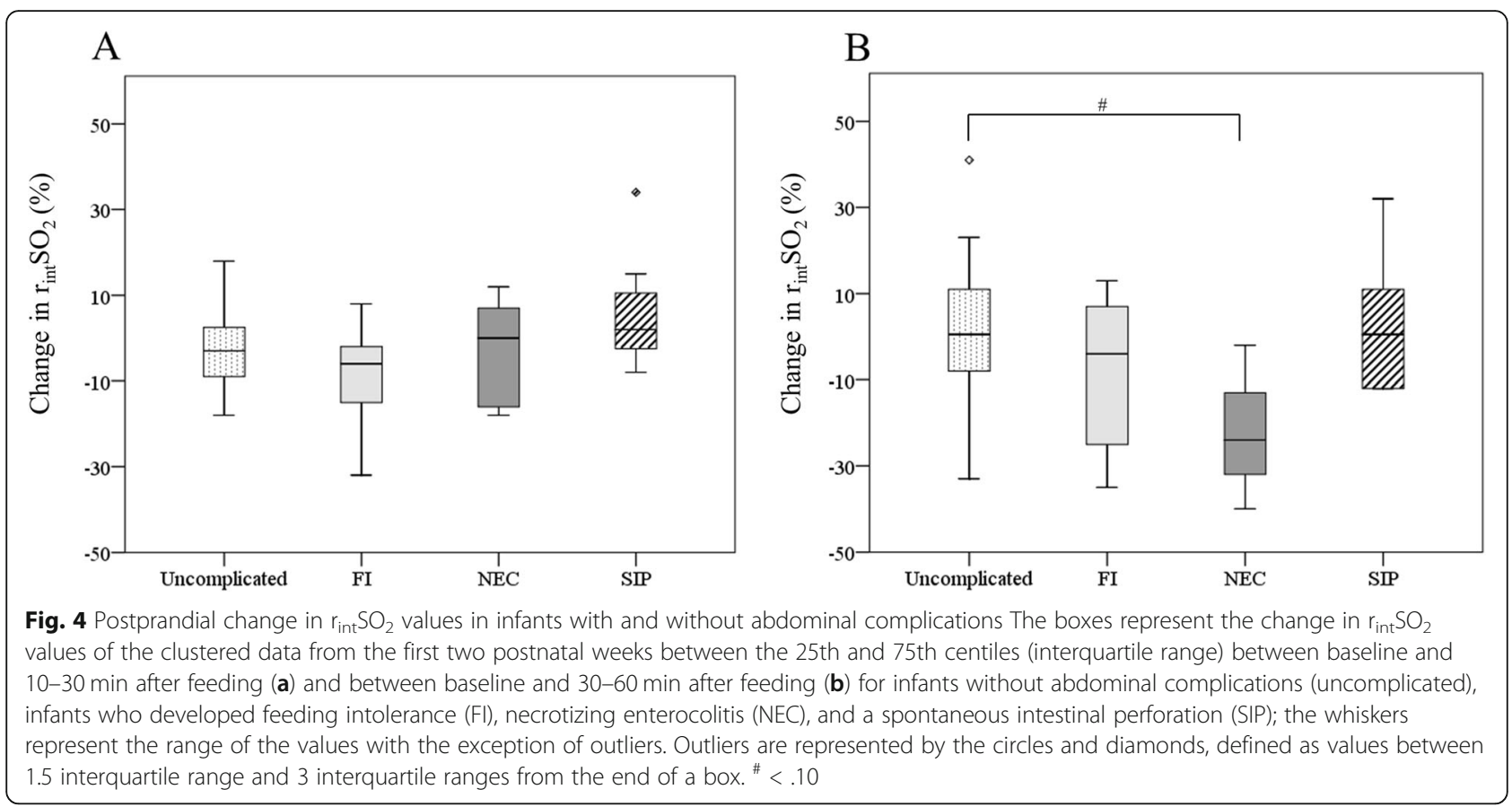

We did not observe an association between postprandially increased intestinal oxygen saturation and postprandially decreased cerebral oxygen saturation. On the contrary, we did find an association between a lack of a postprandial increase of the intestinal $\mathrm{rSO}_{2}$ and the risk of a decreased cerebral $\mathrm{rSO}_{2}$. We hypothesize that the infants with a lower PMA, who more often seemed to lack an adequate intestinal response, might have a less adequate cerebrovascular autoregulation and thus are at risk of compromised cerebral perfusion. A decrease of the cerebral oxygen saturation might indicate a decreased systemic circulation. One of the reasons for a decreased systemic circulation might be a lower cardiac output, but this might also be due to changes in blood pressure or redistribution of blood flow to other vital organs that temporarily have an increased metabolic demand. As the cerebral oxygen saturation is not a measure for cardiac output, assumptions concerning a decrease in cardiac output, or to what extent the cardiac output might have changed, cannot be made. Previously, stable cerebral oxygen saturation values were reported in studies that evaluated the effect of enteral feeding on $\mathrm{rSO}_{2}$ in preterm infants $[2,16,33,34]$. Combining these results with our results suggests that cerebral saturation is not compromised when intestinal perfusion increases after enteral bolus feeding, possibly on account of adequate cerebrovascular autoregulation, but that this may be age-dependent.

In our study, only a few infants developed NEC. The infants who subsequently developed NEC tended to have a decreasing intestinal oxygen saturation 30-60 min after bolus feeding during the first two postnatal weeks, whereas infants without GI complications, FI, and SIP did not. As a result of the very small number of infants, these results have to be carefully interpreted, and conclusions cannot be made based on these results, which require further investigation in a larger cohort.

An important strength of this exploratory study is the longitudinal design that created the opportunity to address the age-dependent component on the effect of enteral feeding on intestinal perfusion. Nevertheless, we also recognise several limitations to our study. The first limitation was the relative small population studied. Therefore we could not analyse the influence of comorbidities on intestinal perfusion after enteral feeding. Neither could we stratify the study cohort on the basis of feeding intervals or feeding type, nor could we perform multivariable regression analyses to test for possible confounding factors. Despite the fact that we performed several tests we chose not to correct for multiple testing, because we considered this observation to be exploratory and hypothesis generating. Another limitation concerns validity issues using NIRS to assess intestinal oxygenation. Movement of the gut, abdominal gasses, and stools could influence the signal because of absorption changes of the near-infrared light which is path-length dependent [6, 14, 31, 32, 35]. Additionally, standard limits of intestinal oxygen saturation are not yet established on account of the wide intervariability and intravariability of intestinal $\mathrm{rSO}_{2}$ values $[14,16]$. Finally, we clustered our data to determine whether the effect of enteral feeding on the intestinal $\mathrm{rSO}_{2}$ depends on PMA. 
Therefore the contribution of measurements per infant was unequally distributed and we might have underestimated or overestimated our results. Nevertheless, to our knowledge, this is the first longitudinal study demonstrating that enteral feeding only affects intestinal oxygen saturation after weeks, or when infants have reached 32 weeks PMA, and larger volumes of feeds.

\section{Conclusions}

Our results suggest that postprandial intestinal hyperaemia does only occur at group level from the fifth week after birth or in infants with relatively older corrected gestational ages receiving a greater amount of enteral feeding. In addition, we showed that postprandial intestinal hyperaemia is not associated with compromised cerebral perfusion. Our study provides more insight into the intestinal physiologic response to enteral feeding in preterm infants. A better understanding of this intestinal physiologic postprandial response might support clinicians in identifying infants at risk for the development of GI complications. This exploratory study, however, raises questions about when and why intestinal saturation does or does not increase after enteral bolus feeding in the early postnatal weeks of a preterm infant, and whether a decreasing intestinal perfusion after feeding may be associated with GI complications later on. Further study is required to address these issues. Moreover, larger studies addressing possible confounders on the intestinal haemodynamic response to enteral feeds, such as PDA and other perinatal morbidities, are needed.

\begin{abstract}
Abbreviations
BW: Birth weight; cFTOE: cerebral fractional tissue oxygen extraction; CHD: Congenital heart disease; FEF: Full enteral feeding; FI: Feeding intolerance; FTOE: Fractional tissue oxygen extraction; GA: Gestational age; Gl: Gastrointestinal; intFTOE: intestinal fractional tissue oxygen extraction; NEC: Necrotizing enterocolitis; NICU: Neonatal intensive care unit; NIRS: Nearinfrared spectroscopy; PDA: Patent ductus arteriosus; PMA: Postmenstrual age; PNA: Postnatal age; $r_{\mathrm{C}} \mathrm{SO}_{2}$ : Regional cerebral tissue oxygen saturation; $\mathrm{r}_{\text {int }} \mathrm{SO}_{2}$ : Regional intestinal oxygen saturation; $\mathrm{rSO}_{2}$ : Regional tissue oxygen saturation; SE: Standard error of the mean; SMA: Superior mesenteric artery; $\mathrm{SpO}_{2}$ : Arterial oxygen saturation
\end{abstract}

\section{Acknowledgements}

We would like to acknowledge the nurses and medical staff of the neonatal intensive care unit of Beatrix Children's Hospital in Groningen, the Netherlands for helping to collect the data and for creating the opportunity to carry out this study. We also greatly acknowledge the patients and their parents for participating. Furthermore, we would like to acknowledge the medical students who helped to collect the data. Finally, we acknowledge Dr. Titia van Wulfften Palthe for correcting the English manuscript.

\section{Authors' contributions}

SK, EK, and AB conceptualized and designed the study. AvZ, and SK collected the data. SK analysed the data and drafted the initial manuscript. KVB performed the multi-level analysis and was responsible for writing that part of the manuscript. EK supervised the study. AvZ, AB, KVB, JH, and EK reviewed and revised the manuscript critically. All authors approved the final manuscript as submitted.

\section{Funding}

This study was part of the research programme of the postgraduate schoo for Behavioural and Cognitive Neurosciences, University of Groningen. S.J. Kuik and A.G.J.F. van Zoonen were financially supported by a grant from the Junior Scientific Master Class of the University of Groningen, Groningen, the Netherlands. This grant was used for a contribution to the PhD fee and for the application of the NIRS neonatal SomaSensors.

\section{Availability of data and materials}

The data sets generated and analysed during this study are available from the corresponding author on reasonable request.

\section{Ethics approval and consent to participate}

This study involved human participants. All the procedures carried out in the context of this study were in accordance with the ethical standards of our institutional and/or national research ethics committee and with the 1964 Helsinki Declaration and its amendments or comparable ethical standards. The study was approved by the ethical review board of University Medical Center Groningen, the Netherlands. Informed consent was obtained in writing from all the parents of the participating infants.

\section{Consent for publication}

For the purpose of this study we did not use any individual person's data, such as images, videos, or other personal details.

\section{Competing interests}

The authors declare that they have nothing to disclose, financially or otherwise. No conflicts of interest were reported.

\section{Author details}

${ }^{1}$ University of Groningen, University Medical Center Groningen, Beatrix Children's Hospital, Division of Neonatology, Groningen, the Netherlands. ${ }^{2}$ University of Groningen, University Medical Center Groningen, Department of Surgery, Division of Pediatric Surgery, Groningen, the Netherlands.

Received: 24 May 2019 Accepted: 28 October 2019

Published online: 04 November 2019

\section{References}

1. Thureen PJ, Hay WW Jr. Early aggressive nutrition in preterm infants. Semin Neonatol. 2001;6:403-15.

2. Corvaglia L, Martini S, Battistini B, Rucci P, Aceti A, Faldella G. Bolus vs. continuous feeding: effects on splanchnic and cerebral tissue oxygenation in healthy preterm infants. Pediatr Res. 2014;76:81-5.

3. Lane AJ, Coombs RC, Evans DH, Levin RJ. Effect of feed interval and feed type on splanchnic haemodynamics. Arch Dis Child Fetal Neonatal Ed. 1998; 79:F49-53.

4. Hsu CH, Lee HC, Huang FY. Duplex ultrasonographic assessment of gut blood flow velocity: effect of meal composition in normal full-term newborns after first feed. J Ultrasound Med. 1994;13:15-8.

5. Lin PW, Stoll BJ. Necrotising enterocolitis. Lancet. 2006;368:1271-83.

6. Patel AK, Lazar DA, Burrin DG, et al. Abdominal near-infrared spectroscopy measurements are lower in preterm infants at risk for necrotizing enterocolitis. Pediatr Crit Care Med. 2014;15:735-41.

7. Corvaglia L, Martini S, Battistini B, Rucci P, Faldella G, Aceti A. Splanchnic oxygenation at first enteral feeding in preterm infants: correlation with feeding intolerance. J Pediatr Gastroenterol Nutr. 2017;64:550-4.

8. Gillam-Krakauer M, Cochran CM, Slaughter JC, Polavarapu S, McElroy SJ, Hernanz-Schulman M, Engelhardt B. Correlation of abdominal rSO2 with superior mesenteric artery velocities in preterm infants. J Perinatol. 2013;33: 609-12.

9. Kooi EMW, Verhagen EA, Elting JWJ, Czosnyka M, Austin T, Wong FY, Aries $\mathrm{MJH}$. Measuring cerebrovascular autoregulation in preterm infants using near-infrared spectroscopy: an overview of the literature. Expert Rev Neurother. 2017;17:801-18.

10. Wong FY, Leung TS, Austin T, Wilkinson M, Meek JH, Wyatt JS, Walker AM. Impaired autoregulation in preterm infants identified by using spatially resolved spectroscopy. Pediatrics. 2008;121:e604-11.

11. Wong FY, Silas R, Hew S, Samarasinghe T, Walker AM. Cerebral oxygenation is highly sensitive to blood pressure variability in sick preterm infants. PLoS One. 2012;7:e43165. 
12. Marin T, Moore J. Understanding near-infrared spectroscopy. Adv Neonatal Care. 2011;11:382-8.

13. Naulaers G, Meyns B, Miserez M, Leunens V, Van Huffel S, Casaer P, Weindling $\mathrm{M}$, Devlieger $\mathrm{H}$. Use of tissue oxygenation index and fractional tissue oxygen extraction as non-invasive parameters for cerebral oxygenation. A validation study in piglets. Neonatology. 2007; 92:120-6.

14. Cortez J, Gupta M, Amaram A, Pizzino J, Sawhney M, Sood BG. Noninvasive evaluation of splanchnic tissue oxygenation using near-infrared spectroscopy in preterm neonates. J Matern Fetal Neonatal Med. 2011;24: 574-82.

15. Dani C, Pratesi S, Barp J, Bertini G, Gozzini E, Mele L, Parrini L. Near-infrared spectroscopy measurements of splanchnic tissue oxygenation during continuous versus intermittent feeding method in preterm infants. J Pediatr Gastroenterol Nutr. 2013;56:652-6.

16. Dave V, Brion LP, Campbell DE, Scheiner M, Raab C, Nafday SM. Splanchnic tissue oxygenation, but not brain tissue oxygenation, increases after feeds in stable preterm neonates tolerating full bolus orogastric feeding. J Perinatol. 2009:29:213-8.

17. Bozzetti V, Paterlini G, De Lorenzo P, Gazzolo D, Valsecchi MG, Tagliabue PE. Impact of continuous vs bolus feeding on splanchnic perfusion in very low birth weight infants: A randomized trial. J Pediatr. 2016;176:86-92.e2.

18. Schat TE, van Zoonen AGJF, van der Laan ME, Mebius MJ, Bos AF, Hulzebos $\mathrm{CV}$, Boezen HM, Hulscher JBF, Kooi EMW. Early cerebral and intestinal oxygenation in the risk assessment of necrotizing enterocolitis in preterm infants. Early Hum Dev. 2019;131:75-80.

19. van Zoonen AGJF, Hulzebos CV, Muller Kobold AC, Kooi EMW, Bos AF, Hulscher JBF. Serial fecal calprotectin in the prediction of necrotizing enterocolitis in preterm neonates. J Pediatr Surg. 2019:54:455-9.

20. Hammers AL, Sanchez-Ramos L, Kaunitz AM. Antenatal exposure to indomethacin increases the risk of severe intraventricular hemorrhage, necrotizing enterocolitis, and periventricular leukomalacia: a systematic review with metaanalysis. Am J Obstet Gynecol. 2015; 212: 505.el-13.

21. Mesquita M, Alvarez E, Godoy L, Avalos S. Scores de gravedad SNAP II y SNAPE I| en la determinación de riesgo de mortalidad neonatal en una unidad de cuidados intensivos polivalente. Pediatría. 2011;38: 93-100.

22. McNeill S, Gatenby JC, McElroy S, Engelhardt B. Normal cerebral, renal and abdominal regional oxygen saturations using near-infrared spectroscopy in preterm infants. J Perinatol. 2011;31:51-7.

23. Campbell MJ, Swinscow TDV. Statistics at square one. 11th ed. Oxford: Blackwell Publishing; 2009. p. 46-7.

24. Curran-Everett D. Explorations in statistics: standard deviations and standard errors. Adv Physiol Educ. 2008:32:203-8.

25. Snijders TAB, Bosker RJ. Multilevel analysis: an introduction to basic and advanced multilevel modeling. London: Sage; 1999.

26. Soleymani S, Borzage M, Seri I. Hemodynamic monitoring in neonates: advances and challenges. J Perinatol. 2010;30:538-45.

27. Neu J. Gastrointestinal maturation and implications for infant feeding. Early Hum Dev. 2007:83:767-75.

28. Bohlen $\mathrm{HG}$. Intestinal tissue $\mathrm{PO}_{2}$ and microvascular responses during glucose exposure. Am J Phys. 1980;238:164-71.

29. Kvietys P. R, Pittman R. P, Chou C.C. Contribution of luminal concentration of nutrients and osmolality to postprandial intestinal hyperemia in dogs. Proc Soc Exp Biol Med 1976;152:659-663.

30. Havranek T, Rahimi M, Hall H, Armbrecht E. Feeding preterm neonates with patent ductus arteriosus (PDA): intestinal blood flow characteristics and clinical outcomes. J Matern Fetal Neonatal Med. 2014:1-5

31. Braski K, Weaver-Lewis K, Loertscher M, Ding Q, Sheng X, Baserga M. Splanchnic-cerebral oxygenation ratio decreases during enteral feedings in anemic preterm infants: observations under near-infrared spectroscopy. Neonatology. 2018;113:75-80.

32. Martini S, Aceti A, Beghetti I, Faldella G, Corvaglia L. Feed-related splanchnic oxygenation in preterm infants with abnormal antenatal doppler developing gut complications. J Pediatr Gastroenterol Nutr. 2018;66:755-9.

33. Martinussen M, Brubakk AM, Vik T, Yao AC. Mesenteric blood flow velocity and its relation to transitional circulatory adaptation in appropriate for gestational age preterm infants. Pediatr Res. 1996;39:275-80.
34. Bembich S, Cont G, Bua J, Orlando C, Di Benedetto D, Demarini S. Bolus feeding has no effect on cerebral hemodynamics, irrespective of gestational age. J Matern Fetal Neonatal Med. 2017;30:1029-31.

35. Bozzetti V, Paterlini G, Meroni V, DeLorenzo P, Gazzolo D, Van Bel F, Visser $\mathrm{GH}$, Valsecchi M, Tagliabue PE. Evaluation of splanchnic oximetry, doppler flow velocimetry in the superior mesenteric artery and feeding tolerance in very low birth weight IUGR and non-IUGR infants receiving bolus versus continuous enteral nutrition. BMC Pediatr. 2012;12:106.

\section{Publisher's Note}

Springer Nature remains neutral with regard to jurisdictional claims in published maps and institutional affiliations.
Ready to submit your research? Choose BMC and benefit from:

- fast, convenient online submission

- thorough peer review by experienced researchers in your field

- rapid publication on acceptance

- support for research data, including large and complex data types

- gold Open Access which fosters wider collaboration and increased citations

- maximum visibility for your research: over $100 \mathrm{M}$ website views per year

At BMC, research is always in progress.

Learn more biomedcentral.com/submissions 